\title{
A ADPF 153, o SOLIPSIMO E A SUBJETIVIDADE NA CONSTRUÇão DA MEMÓRIA E NA CONSTRUÇÃo NORMATIVA
}

\author{
The ADPF 153 and subjectivity in the construction of memory \\ and normative construction
}

\begin{abstract}
André Luís Vieira Elói
Advogado. Graduado em Direito pela Pontifícia Universidade Católica de Minas Gerais (PUC-Minas). Especialista em Direito Processual pelo Instituto de Educação Continuada da PUC-Minas e mestrando em Teoria do Direito no Programa de

Pós Graduação em Direito da PUC-Minas. E-mail: eloi.andreluis@gmail.com
\end{abstract}

RECEBIDO EM: 11.09.2012

AProvado EM: 04.12.2012

\section{RESUMO}

O presente artigo pretende refletir a respeito da decisão da ADPF 153, sua nítida dissonância com a constituição e ineficácia na aplicação do Direito diante das exigências apresentadas pelo Estado Democrático de Direito. Utilizando como referencial o voto do ministro relator do julgamento, Eros Grau, percebemos a tentativa de reconstrução da memória do período da ditadura onde se deu a promulgação da anistia, passando uma idéia de celebração de um acordo pacífico dentro da sociedade brasileira, com um perdão geral e irrestrito para todos os abusos cometidos na ditadura. Através dos conceitos e explanações de Ost acerca de como a formação da memória se dá de maneira coletiva, ficará clara a intenção de se construir uma história oficial que esconda erros e abusos cometidos. Ricoeur define este abuso como memória impedida. Também, analisando o voto do ministro, vemos erros graves de interpretação/ aplicação do direito em um paradigma de Estado Democrático de Direito. A decisão criticada interpreta a lei da anistia através de uma tentativa do intérprete de se colocar no lugar do legislador, para compreender sua intenção 
no momento da promulgação. Gadamer nos demonstra a impossibilidade de tal feito, por estarmos em contextos históricos diferentes. Para isso, serão expostos alguns conceitos apresentados por Gadamer na construção do seu circulo hermenêutico, para que se possa compreender de que maneira sua concepção de interpretação e aplicação, além dos efeitos da tradição, podem contribuir para a construção do direito de maneira mais adequada às exigências do Estado Democrático de Direito.

Palavras-chave: Memória. Hermenêutica filosófica. Constituição. ESTADO DEMOCRÁTICO DE DIREITO.

\section{Abstract}

This article intends to reflect on the decision of the ADPF 153, and his sharp disagreement with the constitution and inefficiency in applying the law to the demands made by the democratic rule of law. Using as reference the vote of justice rapporteur of the trial, Eros Grau, we see the attempt to reconstruct the memory of the dictatorship period where they gave the promulgation of the amnesty, from an idea to conclude a peaceful agreement in Brazilian society, with a pardon general and unrestricted for all abuses committed during the dictatorship. The concepts and explanations of Ost on the formation of memory of how it happens collectively, will clear the intention to build an official history that hides mistakes and abuses. Ricoeur defines such abuse as memory prevented. Also, analyzing the vote of Justice, we see serious errors of interpretation / application of law in a paradigm of a democratic state. The decision criticized interprets the law of amnesty through an attempt to interpret the legislature put in place to understand their intention at the time of enactment. Gadamer shows us the impossibility of such a feat by being in different historical contexts. For this, we introduce some concepts presented by Gadamer in building its hermeneutic circle, so you can understand how his conception of interpretation and application, and the effects of tradition, can contribute to the construction of the law in a manner best suited to the requirements democratic rule of law.

Keywords: Memory. Philosophical hermeneutics. Constitution. DEMOCRATIC STATE LAW.

SuMÁRIo: Introdução. 1. A tentativa de impedir a memória. 2. Dos equívocos na aplicação do direito ao caso concreto. Conclusão. Referências. 


\section{INTRODUÇÃO}

A Arguição de Descumprimento de Preceito Fundamental, de número 153, cujo pedido consistia na interpretação da lei 6.683/79 (lei da anistia), conforme a Constituição, para declarar que a anistia concedida no artigo $1^{\circ}$ não se estenderia aos crimes comuns e violações de direitos humanos praticados por agentes públicos durante a ditadura militar.

A propositura desta ação visava que, através do poder judiciário, fosse recontada a história do período de exceção da ditadura militar, como forma de viabilizar a consolidação do Estado Democrático de Direito, atribuindo responsabilidades a quem cometeu abusos, principalmente violações de direitos humanos durante a ditadura e reconhecendo as vítimas, demonstrar a preocupação do Estado em protegê-las e resguardar os cidadãos de novas ameaças totalitárias.

Entretanto, a decisão do Supremo Tribunal Federal se esqueceu (ou fingiu que esqueceu) de tudo que ocorreu no Brasil durante o período de ditadura, tentando "varrer para baixo do tapete" os problemas e abusos cometidos durante o regime de exceção.

No presente trabalho são tecidas críticas a esta decisão através da análise de conceitos trazidos por François Ost, Paul Ricoeur e Hans-Georg Gadamer.

Ost e Ricoeur nos trazem grandes contribuições na explanação de como a memória é formada de forma coletiva, sendo que, mesmo nossas íntimas lembranças, são guiadas por referências trazidas pela coletividade na qual estamos inseridos, além de demonstrar algumas formas de abuso de memória que se encaixam na crítica à narrativa histórica feita no voto do ministro relator do julgamento da ADPF, Eros Grau.

Já Gadamer, através de sua hermenêutica filosófica e seus conceitos de tradição e história efeitual, insere o juiz (intérprete do direito) dentro do seu objeto de interpretação (o próprio Direito) tornando-o co-responsável pela sua construção, mas também um produto do próprio objeto, que já traz consigo uma carga de conceitos, práticas e tradições, repassadas através da linguagem ao próprio intérprete, estando ele consciente disso, ou não.

Os atos de narrar e decidir, a partir das teorias que serão abordadas, deixam de ser atos de vontade do juiz se tornando conseqüências racionais da história que os precede, e na qual estão inseridos, havendo efeitos de um sobre o outro de maneira constante e inevitável.

A partir dessas premissas ficam claros os graves equívocos cometidos no julgamento da ADPF 153. 


\section{A tentativa de IMPedir a MeMória}

O julgamento da ADPF 153 apresentou um grave problema em sua fundamentação. No voto do relator, o então ministro Eros Grau (e também em outros votos como o da ministra Cármen Lúcia), para justificar a não declaração dos crimes que violaram direitos humanos como não incluídos no rol do art. $1^{\circ}$ da lei de anistia, ele se utilizou de uma reconstrução histórica do momento onde foi promulgada a referida lei.

Segundo o ministro, a lei de anistia foi o resultado de um acordo pacífico entre os governantes militares e seus opositores. Nas palavras do próprio ministro:

43. Há quem se oponha ao fato de a migração da ditadura para a democracia política ter sido uma transição conciliada, suave em razão de certos compromissos. Isso porque foram todos absolvidos, uns absolvendo-se a si mesmos. Ocorre que os subversivos a obtiveram, a anistia, à custa dessa amplitude. Era ceder e sobreviver ou não ceder e continuar a viver em angústia (em alguns casos, nem mesmo viver). Quando se deseja negar o acordo político que efetivamente existiu resultam fustigados os que se manifestaram politicamente em nome dos subversivos. Inclusive a OAB, de modo que nestes autos encontramos a $\mathrm{OAB}$ de hoje contra a $\mathrm{OAB}$ de ontem. É inadmissível desprezarmos os que lutaram pela anistia como se o tivessem feito, todos, de modo ilegítimo. Como se tivessem sido cúmplices dos outros. Para como que menosprezá-la, diz-se que o acordo que resultou na anistia foi encetado pela elite política. Mas quem haveria de compor esse acordo, em nome dos subversivos? O que se deseja agora, em uma tentativa, mais do que de reescrever, de reconstruir a História? Que a transição tivesse sido feita, um dia, posteriormente ao momento daquele acordo, com sangue e lágrimas, com violência? Todos desejavam que fosse sem violência, estávamos fartos de violência ${ }^{1}$.

Todavia, este argumento se mostra extremamente frágil e perigoso. Quando o próprio ministro afirma que "era ceder e sobreviver", já fica claro que não houve nenhuma negociação entre os "subversivos" e a ditadura.

Na verdade, a anistia foi uma auto-anistia dos ditadores, que na iminência do fim de seu regime de exceção buscavam se resguardar de punições futuras. Então, se aproveitaram da fragilidade daqueles que estavam sendo perseguidos pelo regime. Podemos descrever a situação dos "subversivos" como similar a alguém que se encontra com uma faca no pescoço e aceita determinada ordem sob a iminência da morte, para promulgar uma lei "pacificadora".

\footnotetext{
${ }^{1}$ Disponível em: http://www.stf.jus.br/arquivo/cms/noticiaNoticiaStf/anexo/ADPF153.pdf.
} 
Como falar de "transição conciliada" quando a aceitação da anistia era condição de sobrevivência para um dos lados? Como falar de acordo válido em uma situação de disparidade tão grande entre as partes interessadas? Tal posicionamento se mostra uma ofensa aos que sofreram com os abusos do regime militar e que não têm reconhecida pelo Estado sua condição de vítima.

A construção da memória oficial, por estarmos em um Estado Democrático de Direito não pode se dar de forma isolada, segundo concepções individuais de um julgador, ou mesmo acatar um posicionamento posto por um paradigma anterior, principalmente se tratando de um estado de exceção.

Segundo François Ost:

A primeira forma do tempo jurídico instituinte é a da memória. A memória que lembra existir o dado e o instituído. Acontecimentos que importam e ainda importam e são suscetíveis de conferir um sentido (uma direção e uma significação) à existência coletiva e aos destinos individuais. Instituir o passado, certificar os fatos acontecidos, garantir a origem dos títulos, das regras, das pessoas e das coisas: eis a mais antiga a mais permanente das funções do jurídico. Na falta de tais funções, surgiria o risco da anomia, como se a sociedade construísse sobre areia (OST, 2005, p. 49).

Ost nos ensina que a leitura que fazemos do passado constitui nossa forma de compreensão do presente e demonstra as expectativas que temos para com o futuro. Uma leitura equivocada e inverídica desse passado pode nos levar a construir um presente frágil, que será o alicerce fadado à ruína do futuro. Ele diz que "uma sociedade amputada de suas raízes, órfã de sua história, encontra barrado seu acesso ao futuro" (OST, 2005, p. 29).

Para entendermos a gravidade dessa reconstrução histórica realizada pelo relator no julgamento da ADPF, a compreensão de dois conceitos explanados por Ost, se mostra bastante interessante: o conceito de memória coletiva e o de memória histórica.

Mesmo as lembranças íntimas de uma pessoa são, por esta, compreendidas se baseando em signos, referências, conceitos trazidos pela tradição através da linguagem. Nas palavras de Ost:

Acontece que nossas lembranças, até as pessoais e mais íntimas, só conseguem se exprimir em termos tomados de empréstimo à tradição; eles só fazem sentido, por outro lado, sendo tomados por uma comunidade afetiva e social que não demora em retrabalhá-los. Só nos lembramos, então, sob a condição de nos colocarmos no meio desta ou daquela corrente de pensamento coletivo e adotar seu ponto de vista (OST, 2005, p. 57). 
Ele define memória coletiva como a memória "viva", aquela que está próxima dos acontecimentos, que ainda é influenciada pela experiência daqueles que nela estão inseridos.

Já a memória histórica é aquela que engendra um saber histórico, é a narrativa dos fatos "com uma certa distância", a partir de dados do presente, que já nos trouxe interpretações intermediárias e sucessivas na construção narrativa (tradição).

A partir desta concepção coletiva da narrativa histórica fica claro um dos erros graves do voto do ministro relator. A elaboração de uma narrativa de suposta harmonia e de acordo pacífico na criação da lei de anistia, demonstra a intenção de construção de uma memória histórica oficial que justifique a manutenção da lei de anistia e sua interpretação como instrumento de perdão geral.

Contudo, as lembranças daqueles que não compartilham da narrativa oficializada pela decisão da ADPF (por ainda estarmos relativamente próximos ao evento), que instituem a memória coletiva, demonstram claramente o viés político que foi adotado na decisão do STF e um abuso da memória.

No livro "A memória, a historia, o esquecimento", Paul Ricoeur define três formas abuso da memória: a memória impedida, a memória manipulada e a memória obrigada.

A memória manipulada diz respeito às manipulações realizadas para distorcer o passado de forma a justificar ou legitimar um poder vigente.

A memória obrigada é aquela onde uma lembrança traumática de uma sociedade de maneira arbitrária passa a ser tratada pela sociedade de maneira heróica, é transformada em um objeto de comemoração.

Já a memória impedida é aquela na qual o poder vigente tenta apagar determinados fatos, ou visões deste, que não lhe interessem.

No caso da decisão da ADPF 153, fica claro o tipo de abuso de memória ocorrido: a memória impedida.

Ao afirmar em sua narrativa a celebração de um acordo permeado de harmonia e reafirmar a idéia de um perdão universal em nítida contradição ao que a própria memória coletiva da sociedade brasileira ainda tem, o STF traz grandes riscos para a construção do presente e, conseqüentemente, do futuro, pois o trabalho de memória é que torna possível que uma determinada coletividade possa ter um presente sem tormentas e um futuro mais esperançoso.

Novamente, ressaltando que, a forma como os atos do regime militar são percebidos pelo povo e pelo Estado influenciam diretamente como serão tratados os crimes realizados no passado. Por isso o abuso de memória realizado pelo STF na decisão da ADPF 153, se mostra de grande perigo para a formação de nosso futuro. 
A aplicação da Lei da anistia como ampla e irrestrita, na realidade é um meio jurídico para afastar a punição dos comandantes de um regime sangrento e covarde.

Outrossim, esse meio representa risco para a consolidação da democracia, pois coloca no mesmo patamar as lutas pela liberdade e a violência de um regime autocrático.

\section{Dos equívocos na APLICAÇão do diREITO AO CASO CONCRETO}

Além do erro na construção de uma memória oficial, o voto do ministro relator apresentou erros graves e perigosos de aplicação do direito, problemas hermenêuticos.

No voto analisado fica claro o posicionamento do ministro de que a lei da anistia deveria ser interpretada através da realidade e do momento histórico no qual foi produzida. Nesta concepção o intérprete/aplicador do direito deveria se colocar no lugar do legislador para, a partir de uma suposta intenção, em um determinado momento histórico, compreender o que este desejava prescrever.

$\mathrm{O}$ voto demonstra uma maneira de ver o direito alheia à realidade onde o intérprete se encontra, e este próprio se coloca de maneira externa ao problema, como se não sofresse influências da história e da tradição nas quais está inserido.

Ora, como pode um ministro de um tribunal constitucional (ou que pelo menos fora criado para o ser), que deve zelar pela compatibilidade do ordenamento jurídico com o texto constitucional, tentar interpretar o direito através de concepções não condizentes com a própria Constituição da qual deveria ser guardião?

Para compreender onde está o erro neste posicionamento a Hermenêutica Filosófica traz contribuições fundamentais.

Gadamer afirma que quando um intérprete busca compreender algum enunciado, não é necessário e nem possível que seja compreendida a constituição psíquica de seu autor, mas sob qual perspectiva ele o formulou. Contudo a sua interpretação deve levar em conta a perspectiva na qual ele se encontra no momento presente.

Segundo a hermenêutica gadameriana o intérprete está inserido em um círculo hermenêutico, que é o espaço onde ocorre a relação dialógica entre o intérprete e a tradição em que está inserido. Por estar inserido neste circulo, a compreensão do leitor de um texto em um determinado momento histórico não será a mesma de outro leitor, inserido em contexto e momento diferentes.

Com isso, Gadamer quer dizer que o sentido de um texto é determinado pelo tempo e contexto histórico nos quais o leitor está inserido. Ele não se 
esgota no momento em que o autor o escreveu, é um processo infinito.

A partir disso a interpretação deixa de ser uma manifestação de vontade, uma escolha do intérprete, sendo resultado de condições pré-estabelecidas social e historicamente, e a este transmitido pela linguagem (possibilidade de manifestação de sentido):

A verdadeira interpretação jurídica não é aquela feita in abstracto, decorrente de uma leitura da norma em seu sentido geral, fora do tempo e do espaço. A hermenêutica jurídica autêntica é somente a que visa à aplicação concreta da norma a um trecho determinado da vida social (Konkretisierung). (Comparato, in Revista do Instituto de Hermenêutica Jurídica, 2010, p.78).

Ainda na perspectiva gadameriana, a interpretação jurídica depende diretamente do caso concreto, que em momentos históricos diferentes pode encontrar necessidades e soluções diferentes. Interpretar a lei é atribuir sentido a um dispositivo diante de um caso concreto.

Mas como evitar atribuições de sentido subjetivas e arbitrárias no momento da construção normativa?

Daí a importância de se compreender o papel e o significado da tradição, tão defendida e resguardada pelo direito. O homem é um ser inserido em determinado contexto e momento históricos, dos quais a própria tradição é parte fundamental, pois conserva as nossas instituições e comportamentos.

Gadamer, ao defender a importância da tradição,jamais objetivou passar a idéia de que as tradições são inquestionáveis e imutáveis. Pelo contrário, a possibilidade da conservação desta depende de constante colocação à prova (e não pela arbitrariedade). Segundo ele, "a conservação é um ato da razão, ainda que caracterizado pelo fato de não atrair atenção sobre si [...] A conservação representa uma conduta tão livre quanto a destruição e a inovação" (Gadamer, 1997, pp. 422-423).

A partir desta concepção gadameriana da tradição e da consciência da inserção no círculo hermenêutico, a concepção individual do intérprete, ou suas vontades passam a ser irrelevantes. Elas podem valer para sua vida pessoal, mas não podem se sobrepor à Constituição, referencial interpretativo de qualquer ordenamento jurídico, e ao paradigma em que está inserido.

A leitura de qualquer lei, mesmo que anterior à Constituição, deve ser feita através "das lentes" desta, que delineia o paradigma conformador de toda e qualquer interpretação a ser realizada: o Estado Democrático de Direito.

Gadamer, através de sua hermenêutica, acaba com a concepção de afastamento entre direito e intérprete, entre homem e história e demonstra que 
toda e qualquer discussão sobre leis é paradigmática, por estar inserida em um contexto histórico que exerce influência sobre seus sujeitos.

Os efeitos da história operam em toda compreensão, esteja o leitor consciente disso ou não. A reflexão da história nunca é esgotada, pois se encontra na essência do ser histórico que somos (que nunca se esgota no saber-se).

A consciência da história efeitual é a consciência da situação hermenêutica, da situação (âmbito de visão que abarca tudo que é possível de se enxergar a partir de determinado ponto) em que um intérprete se encontra face à tradição que deseja compreender, de seu paradigma.

No caso de lei da anistia, a discussão é parte de um contexto marcado por uma ruptura institucional, com o estabelecimento de (ou transição para) um regime democrático.

A promulgação de uma nova Constituição é um marco, pois, ao estabelecer um novo paradigma (Estado Democrático de Direito), rompe com as práticas anteriores (de um Estado de exceção) que não se mostraram úteis neste novo horizonte de interpretação, e por isso não devem ser consideradas como tradição. E, como já explanado, a tradição não se impõe por arbitrariedades, mas se forma na comprovação da utilidade de práticas e conceitos diante de casos concretos.

Ao decidir se utilizando de uma suposta intenção do legislador da época, o STF ignora o paradigma no qual está inserido e comete, ainda, o absurdo de tentar retomar práticas já superadas, e comprovadamente inválidas, no ordenamento jurídico brasileiro.

Citando Lênio Streck:

A continuidade na tradição obrigará a uma justificação dialogada, controlada e confrontada com essa mesma tradição, o que exclui qualquer resultado e circunscreve a área de compreensão legítima isto será mais correto que se abandonar, com os braços cruzados, a uma metodologia que talvez nos conduza a resultados eficazes, porém, quem controla (essa) metodologia? A resposta a essa pergunta é que a tradição reclamada por Gadamer baseia-se na idéia de uma repetição produtiva no ato originário de criação (Streck, 2011, pp. 275-276).

Ou seja, para Gadamer, por mais que o intérprete se prenda à letra do texto, não há garantia de reprodução do sentido original. Daí a importância de saber o paradigma onde está inserido, pois o que se deve saber ou compreender de um paradigma anterior já foi levado ao intérprete pela linguagem e pela tradição. O que não foi levado a ele, não o foi por não mais ter se mostrado útil diante da realidade que se põe diante dele. 
O voto do ministro Eros Grau, ao deixar de interpretar a lei de anistia de acordo com a Constituição de 1988, representou uma ofensa direta à finalidade do Estado Democrático de Direito de concretização dos Direitos Humanos. Além disso, ignora os tratados internacionais dos quais o Brasil é signatário.

Nas palavras de Fernando Armando Ribeiro:

Constituição será sempre obra de valores predeterminados, advindos da evolução da afirmação da liberdade na história, como manifestação institucional aprimorada do consenso racional. As normas constitucionais serão sempre o momento de concretização desses valores universais, momento substancial e imprescindível, mas que não exaure o plano de verificação deles (Ribeiro, 2004, p. 201).

A ordem constitucional democrática gerada e estruturada sobre a constituição Democrática, não consiste senão na juridicização procedimental e materialmente democrática da relação política "podersujeição" dirigida a racionalizar e a controlar a atuação do Poder Público, bem como assegurar a garantia dos direitos fundamentais de todos (Ribeiro, 2004, p. 97).

A Constituição desempenha papel essencial no Estado Democrático, pois é ela que assegura os direitos fundamentais e impede a opressão, indicando quais direitos são invioláveis, quais princípios devem ser seguidos em nosso ordenamento, e como deve funcionar a prestação jurisdicional.

\section{CONClusão}

Em um contexto de grande diversidade, o Direito, como expressão das regras de funcionamento de uma sociedade, passa a ter, em seu fundamental papel, uma missão muito mais árdua, pois, em um mundo cada vez mais diversificado, se torna uma missão cada dia mais hercúlea manter a correspondência entre direito e a realidade, essencial para a construção da democracia.

A sociedade é resultado de processos comunicativos que acontecem durante sua própria construção. Contudo, esta construção é constante, sendo que a sociedade e o Direito passam por constantes mudanças e estão sob constantes questionamentos.

Os conceitos abordados neste trabalho nos auxiliam de forma decisiva nesta constante reconstrução do direito e da memória, pois superam de forma decisiva a concepção de uma memória individual, de concepções individuais acerca do ordenamento jurídico e de sua construção/aplicação. 
A partir do anti-relativismo que o respeito à tradição, a compreensão do círculo hermenêutico e da história efeitual trazem à construção da memória e da aplicação de normas, foi dado um grande passo na construção do Estado Democrático de Direito, visando o fim do solipsismo e das arbitrariedades.

As obras de Ost, Ricoeur e Gadamer, principais referenciais do presente trabalho, colocam o intérprete/aplicador inserido em um contexto, em um paradigma, e sujeito às influências das tradições que estes trazem consigo. O reconhecimento desta situação traz o intérprete para dentro do objeto de interpretação, tornando-o co-responsável pela sua construção normativa, que não mais pode ser construída de forma subjetiva, mas também um produto do próprio objeto, que já traz consigo uma carga de conceitos, práticas e tradições, repassadas através da linguagem ao próprio intérprete, estando ele consciente disso, ou não.

A partir deste posicionamento, o voto do ministro Eros Grau, a decisão do STF, e seus fundamentos se mostram em total dissonância com o paradigma de Estado Democrático de Direito instaurado pela Constituição, tanto do ponto de vista filosófico e ético (reconstrução de uma narrativa com nítido abuso de memória - memória interrompida), quanto do ponto de vista jurídico (interpretação de leis sem o referencial da Constituição).

Para a consolidação de nossa jovem democracia não podemos nos calar diante de nítidas tentativas de distorção de nossa história, e nem permitir que no contexto histórico e no paradigma jurídico que estamos inseridos, ainda seja possível fazer qualquer interpretação do direito que não parta da Constituição. 


\section{REFERÊNCIAS}

CHAMON Jr., Lúcio Antônio. Teoria da Argumentação Jurídica. Rio de Janeiro: Lúmen Júris, 2008.

GADAMER, Hans Georg. Verdade e Método. Trad. Flávio Paulo Meurer. Petrópolis: Vozes, 1997.

NETTO, Menelick de Carvalho. A interpretação das leis: um problema metajurídico ou uma questão essencial do Direito de Hans Kelsen a Ronald Dworkin. Disponível em: HTTP://www.almg.gov.br/CadernosEscol/Caderno5/ dfi.pdf . Acessado em: 21.03.2009.

OLIVEIRA, Marcelo Andrade Cattoni de. Jurisdição e hermenêutica constitucional: no Estado democrático de direito. Belo Horizonte: Mandamentos, 2004.

OST, François. O tempo do direito. Bauru, SP: Edusc, 2005.

REVISTA DO INSTITUTO de Hermenêutica Jurídica - vol. 8, n.8 (2010), Belo Horizonte: Instituto de Hermenêutica Jurídica, 2003.

RIBEIRO, Fernando Armando. Conflitos no estado constitucional democrático: por uma compreensão jurídica da desobediência civil. Belo Horinzonte: Mandamentos, 2004.

RIBEIRO, Fernando Armando. Desobediência civil: um instituto democrático. In: Revista da Faculdade Mineira de Direito. Belo Horizonte, vol. 8, n. 15, pp. 95-118, 01 sem. 2005.

RIBEIRO, Fernando José Armando; BRAGA, Barbara Gonçalves de Araújo. A Teoria das Fontes do Direito revisitada: uma reflexão a partir do paradigma do estado democrático de direito. Disponível em: http://www.conpedi.org. br/manaus/arquivos/anais/salvador/fernando_jose_armando_ribeiro-1.pdf. Acessado em: 30.03.2012.

RICOEUR, Paul. A memória, a história e o esquecimento. Campinas, SP: Editora da Unicamp, 2007. 